o www.deswater.com

o

doi:10.5004/dwt.2017.20518

\title{
Effects of pre-ozonation in case of microfiltration of oil contaminated waters using polyethersulfone membrane at various filtration conditions
}

\author{
Gábor Veréb*, Mihály Zakar, Ildikó Kovács, Katalin Pappné Sziládi, Szabolcs Kertész, \\ Cecilia Hodúr, Zsuzsanna László
}

Department of Process Engineering, Faculty of Engineering, University of Szeged, H-6725, Moszkvai krt. 9., Szeged, Hungar, email:verebg@mk.u-szeged.hu (G. Veréb),zakarmihaly05@gmail.com (M. Zakar),kovacsildy126@gmail.com (I. Kovács), sziladi@mk.u-szeged.hu (K.P. Sziládi),kertesz@mk.u-szeged.hu(S.Kertész),hodur@mk.u-szeged.hu (C. Hodúr), zsizsu@mk.u-szeged.hu (Z. László)

Received 25 July 2016; Accepted 19 January 2017

\section{A B S T R ACT}

In the present study membrane filtration was applied for the purification of crude oil containing stable oil in water emulsions $\left(\mathrm{c}_{\mathrm{oil}}=100 \mathrm{ppm} ; \mathrm{d}_{\text {oil droplets }}<1.5 \mu \mathrm{m}\right.$ ) with and without pre-ozonation using polyethersulfone (PES) microfiltration membrane $(\mathrm{d}=0.2 \mu \mathrm{m})$. The effect of ozonation on the size of oil droplets and on Zeta-potential was determined by dynamic light scattering measurements. The effects of applied transmembrane pressure, stirring speed and duration of ozonation were investigated in detail. Removal efficiency was determined by measuring turbidity, chemical oxygen demand (COD), total organic carbon content (TOC) and extractable oil content (TOG/TPH). Results pointed out, that short pre-ozonation (absorbed ozone was $30 \pm 5 \mathrm{mg} \mathrm{L}^{-1}$ ) causes increased fluxes and decreased resistance without notable change in the purification efficiency in case of low transmembrane pressure $(0.1 \mathrm{MPa})$. However longer pre-ozonation or higher transmembrane pressure results in increased irreversible resistance, lower permeate fluxes or even lower purification efficiency.

Keywords: Ozonation; Microfiltration; Polyethersulfone; Crude oil; Pressure

\section{Introduction}

One of the most common groups of water pollutants are oily contaminants. As a result of industrial growth increasing amount of oil contaminated waters is produced [1,2]; oily pollutants can appear in ground waters as well, especially in fields of intensive hydrocarbon extraction.

Oil contaminations can be categorized as: free (or floating) oil, dispersed (unstable) oil and (stable) emulsified oil [3-5]. Waters contaminated with free-floating oil $\left(\mathrm{d}_{\text {oil drop lets }}>150 \mu \mathrm{m}[4,6]\right)$ and unstable oil in water emulsions ( $\mathrm{d}_{\text {oil droplets }}$ : $\left.20-150 \mu \mathrm{m}[4]\right)$ can be purified by conventional water treatment techniques $[1,4,5,7-10]$, such as gravity separation, centrifugation [11], skimming [12], flotation [13], or

${ }^{*}$ Corresponding author coagulation $[10,11,14]$. Stable oil in water emulsion is characterized in the literature by oil droplets smaller than $20 \mu \mathrm{m}$ $[4,7,9]$ or smaller than $50 \mu \mathrm{m}$ [15]. However Chakrabarty et al. [5] emphasized that it is difficult to purify those oil contaminated waters which contains smaller oil droplets than $5 \mu \mathrm{m}$. For the purification of stable emulsions conventional techniques are not applicable $[2,16]$, so more effective methods are desired such as membrane filtration, which is one of the most investigated methods for the purification of these kind of emulsions.

Several reports were published in which membrane micro- $[6-9,16-20]$ and/or ultrafiltration [5,8,16,21-24] were applied for the purification of oil contaminated waters. Polysulfone- $[3,5,21]$, polyethersulfone- $[2,16,20,25]$, ceramic- $[9,10,17,19]$, porous glass- [18], carbon- [7] polia-

Presented at the EDS conference on Desalination for the Environment: Clean Water and Energy, Rome, Italy, 22-26 May 2016. 
crilnitril- [8], teflon- [26], polyvinylidene fluoride- [16,26] membranes have already been investigated. Polyethersulfone (PES) is one of the most extensively used membranes, because of its chemical- and thermal stability, easy producibility and environmental endurance $[2,27]$. This hydrophilic material is applicable in case of oil contaminated waters as well. Although membrane separation has many advantages, a major problem of this technique is membrane fouling [1]. Therefore many researchers try to develop novel solutions, such as combined methods $[3,10,28,29]$, modified membrane surfaces $[2,25,27,30]$ or cleaning techniques $[21,31,32]$ to solve this problem. There are many reports in the literature in which membrane separation combined with pre-ozonation resulted in lower filtration resistances and/or fouling or even higher purification efficiency in case of different water contaminants [28,33-37]. Moreover, pre-ozonation resulted in higher fluxes in case of petroleum contaminated water $\left(\mathrm{d}_{\text {oil droplets }}<5 \mu \mathrm{m}\right)$ as it was published in a previous report [20].

In the present study stable oil in water emulsion (contains crude oil; $\mathrm{c}_{\mathrm{oil}}=100 \mathrm{ppm} ; \mathrm{d}_{\text {oil droplets }}<1.5 \mu \mathrm{m}$ ) was purified by microfiltration (PES, $0.2 \mu \mathrm{m})$ with and without ozone pretreatment. The work is focused on the effect of pre-ozonation in case of various transmembrane pressures and stirring intensities in relation to the permeate fluxes, resistances and purification efficiencies.

\section{Materials and methods}

\subsection{Production of stable oil in water emulsion}

The emulsion was prepared in two steps using crude oil (Algyö, Hungary) and distilled water. In the first step 1 wt.\% emulsion was prepared by intensive stirring (35000 rpm), then $5 \mathrm{~mL}$ of this emulsion was inoculated into $495 \mathrm{~mL}$ of distilled water directly below the transducer of an ultrasonic homogenizer (Hielscher UP200S) resulting in stable oil in water emulsion ( $\mathrm{c}_{\mathrm{oil}}=100 \mathrm{ppm}$ ). The duration of homogenization was $10 \mathrm{~min}$, maximal amplitude and cycle was applied and the emulsion was thermostated to $25^{\circ} \mathrm{C}$.

\subsection{Description of oil in water emulsions}

Conductivity and $\mathrm{pH}$ of the emulsions was measured by a Consort C535 type multimeter. The size distribution and Zeta-potentials were determined by dynamic light scattering measurements using a Malvern ZetaSizer4 type equipment.

\subsection{Ozonation}

Ozone was generated from clean oxygen (Messer; 3.5) by a flow-type ozone generator (BMT 802X) and bubbled through a diffuser into a batch reactor (contained $400 \mathrm{~mL}$ of oil in water emulsion) during intensive magnetic stirring. Applied flow rate was $1 \mathrm{~L} \mathrm{~min}^{-1}$, and ozone concentration of inlet and outlet was measured using a WPA Biowave II type UV spectrophotometer at $\lambda=254 \mathrm{~nm}$. Ozonation time was usually $5 \mathrm{~min}$ and in another series of experiments 5,10 and 20 min of ozonation was applied which resulted in 30 $\pm 5,115 \pm 10$ and $290 \pm 15 \mathrm{mg} \mathrm{L}^{-1}$ of absorbed ozone, respec- tively. The remaining dissolved ozone was purged by oxygen bubbling after the treatment to avoid the oxidation of PES membrane.

\subsection{Membrane filtration}

For the membrane filtration experiments a batch-stirred membrane reactor was applied (Millipore XFUF07601) equipped with polyethersulfone (PES) membrane $\left(\mathrm{d}_{\text {pore }}=0.2 \mu \mathrm{m}\right.$; filtration area was $\left.0.00332 \mathrm{~m}^{2}\right)$. Before the experiments membranes were soaked into distilled water for $48 \mathrm{~h}$ in all cases. Applied transmembrane pressures were $0.1,0.2$ and $0.3 \mathrm{MPa}$ (provided by nitrogen gas), while stirring speed was set to be 50, 200 and $350 \mathrm{rpm}$ respectively. The volume of the treated emulsion was $250 \mathrm{~mL}$ and filtration was carried out until $200 \mathrm{~mL}$ of permeate was produced $($ volume reduction ratio $(\mathrm{VRR})=5)$.

\subsection{Determination of purification efficiency}

Purification efficiencies were determined by measuring turbidity (Hach 2100N), chemical oxygen demand (COD) and extractable oil content (TOG/TPH) in all cases. Total organic carbon (TOC) content was also measured when the effect of ozone pretreatment duration was investigated.

COD values were measured by a standard method, based on potassium dichromate oxidation in standard test tubes (Hanna Instruments) using Lovibond ET 108 type digester (for $2 \mathrm{~h}$, at $\mathrm{T}=150^{\circ} \mathrm{C}$ ), and Lovibond COD Vario type spectrophotometer. Extractable oil content was measured by a Wilks InfraCal TOG/TPH type analyzer, using hexane as extracting solvent. TOC values were measured by an Analytik Jena N/C 3100 type equipment $\left(\mathrm{T}=800^{\circ} \mathrm{C}\right.$-on) equipped with an IR detector.

The purification efficiency $(\mathrm{R})$ was determined as:

$R=\left(1-\frac{a}{a_{0}}\right) \cdot 100 \%$

where $a_{0}$ is the turbidity, COD, TOG/TPH or TOC values of the feed while $a$ indicates the values of the permeate.

\subsection{Resistance-in-series model}

The membrane resistance $\left(R_{M}\right)$ was calculated as [38]:

$R_{M}=\frac{\Delta p}{J_{w} \eta_{w}}\left[m^{-1}\right]$

where $\Delta p$ is the transmembrane pressure $(\mathrm{Pa}), J_{W}$ is the water flux of the clean membrane and $\eta_{W}$ is the viscosity of the water (Pas).

The irreversible resistance $\left(R_{\text {Irrev }}\right)$ was determined by re-measuring the water flux on the used membrane after the filtration, followed by a purification step (intensive rinsing with distilled water):

$$
R_{\text {Irreo }}=\frac{\Delta p}{J_{W A} \eta_{W}}-R_{M}\left[\mathrm{~m}^{-1}\right]
$$

where $J_{W A}$ is the water flux after the cleaning procedure. 
The reversible resistance $\left(R_{\text {Rev }}\right)$, caused by not adhered oil layer and concentration polarisation layer can be calculated as:

$$
R_{\mathrm{Re} v}=\frac{\Delta p}{J_{c} \eta_{W W}}-R_{\text {Irrev }}-R_{M}\left[\mathrm{~m}^{-1}\right]
$$

where $J_{c}$ is the flux at the end of the filtration and $\eta_{w w w}$ is the wastewater viscosity. The total resistance $\left(R_{T}\right)$ can be evaluated from the steady-state flux by using the resistance-in-series model:

$$
R_{T}=R_{M}+R_{\text {Irrev }}+R_{\text {Rev }}\left[\mathrm{m}^{-1}\right]
$$

\section{Results and discussion}

\subsection{Effect of pre-ozonation on the properties of oil in water} emulsion

The emulsion production method resulted in the desired stable oil in water emulsion $\left(\mathrm{d}_{\text {oil droplets }}<2 \mu \mathrm{m}\right)$. Fig. 1 demonstrates the size distributions: diameters of oil droplets are between 0.1 and $1.5 \mu \mathrm{m}$ in the untreated emulsion (and average diameter increased only $5 \%$ after five days).

Ozonation significantly reduced the size of oil droplets and Zeta-potential measurements pointed out that ozonation increased the negative surface charge of the droplets (from $-9,6 \mathrm{mV}$ to $-32,-33$ and $-35 \mathrm{mV}$ after 5,10 and 20 min of ozonation respectively), which causes even higher stability. It should be noted that ozonation as an oxidation process can decrease the hydrophobicity of the oil droplets as well. Produced emulsions were slightly acidic ( $\mathrm{pH} 5.2 \pm 0.2$ ), and the $\mathrm{pH}$ value slightly decreased (4.2 \pm 0.2$)$ during ozonation, while the conductivity slightly increased (from $\sim 5 \mu \mathrm{cm}^{-1}$ up to $35 \mu \mathrm{S}$ $\mathrm{cm}^{-1}$ ), which can be explained by the production of dissolved acidic components.

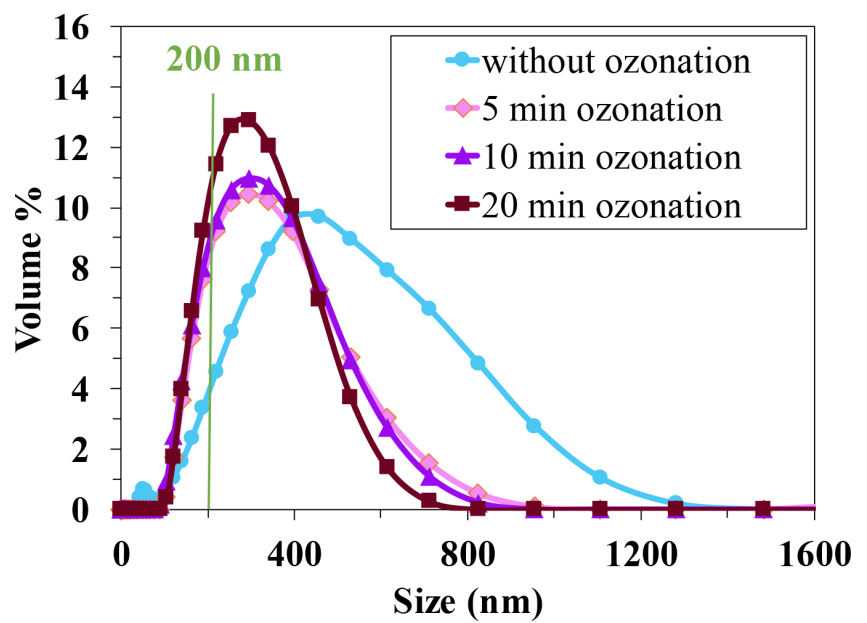

Fig. 1. Size distribution of oil in water emulsions with and without ozonation.

\subsection{Effects of filtration conditions}

Three different transmembrane pressures $(0.1,0.2$ and $0.3 \mathrm{MPa}$ ) and three different stirring speeds (50, 200, $350 \mathrm{rpm}$ ) were applied during the membrane filtration of oil in water emulsions with and without ozone pretreatment. Fig. 2 shows the typical effect of transmembrane pressure and stirring speed on the relative fluxes $\left(J_{\text {emulsion }} / J_{\text {distilled water }}\right)$. Increased stirring speed caused much higher fluxes (at all pressures) while increased transmembrane pressure resulted in lower relative fluxes (at all stirring speeds). Very similar effects were observed both in case of ozone pretreated and in case of not pretreated emulsions.

Determined lower fluxes at higher pressure is in good agreement with the results of Abadi et al. [19], who filtered oily contaminated water using ceramic membrane. Fig. 3 summarizes the calculated resistances of all filtration experiments of pre-ozonized and not pretreated oil in water emulsions. The value of total resistances always decreased with increased stirring speed, while higher pressures causes much higher total resistance (optimal parameters are $0.1 \mathrm{MPa}$ and $350 \mathrm{rpm}$ ) both in case of pre-ozonized or not pretreated emulsions. However in case of pre-
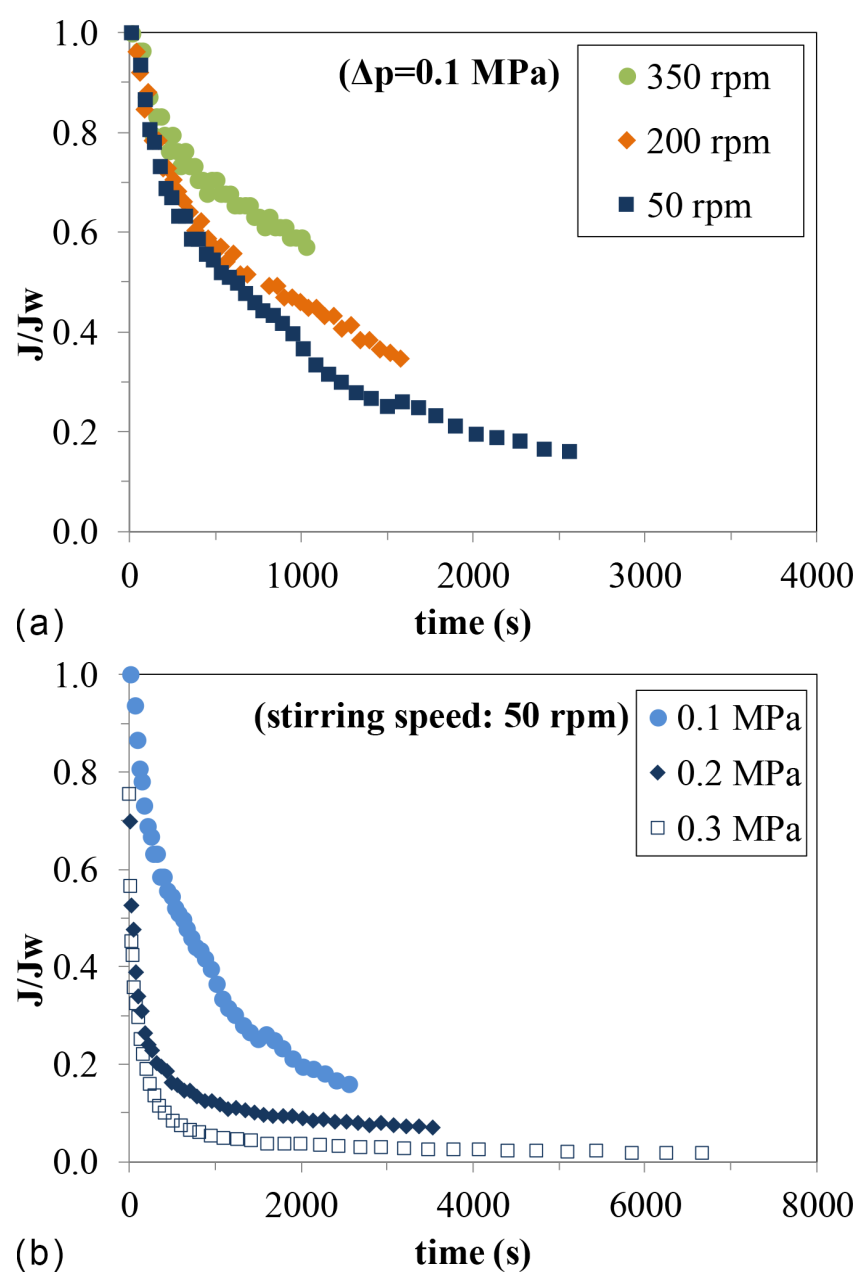

Fig. 2. Effect of stirring speed (a) and transmembrane pressure (b) on the relative fluxes (In case of the filtration of ozone pretreated oil in water emulsion). 


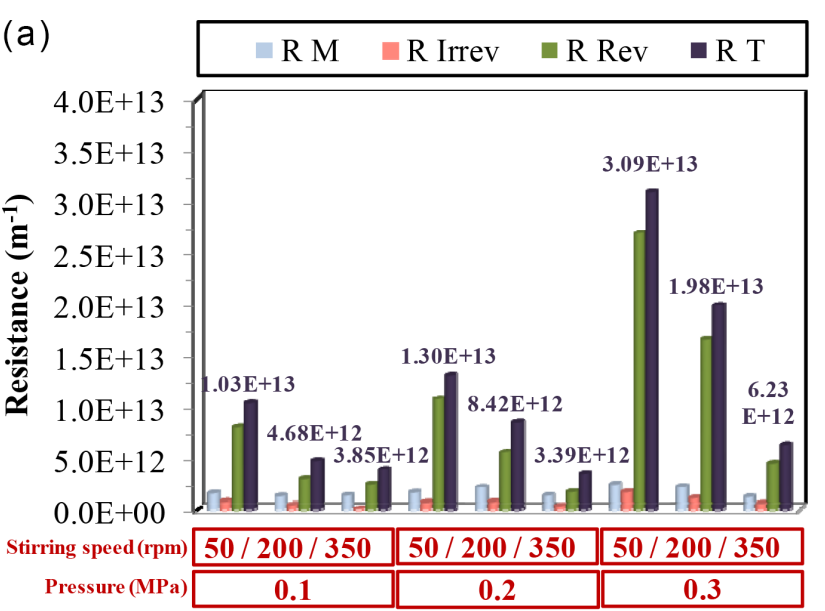

(b)

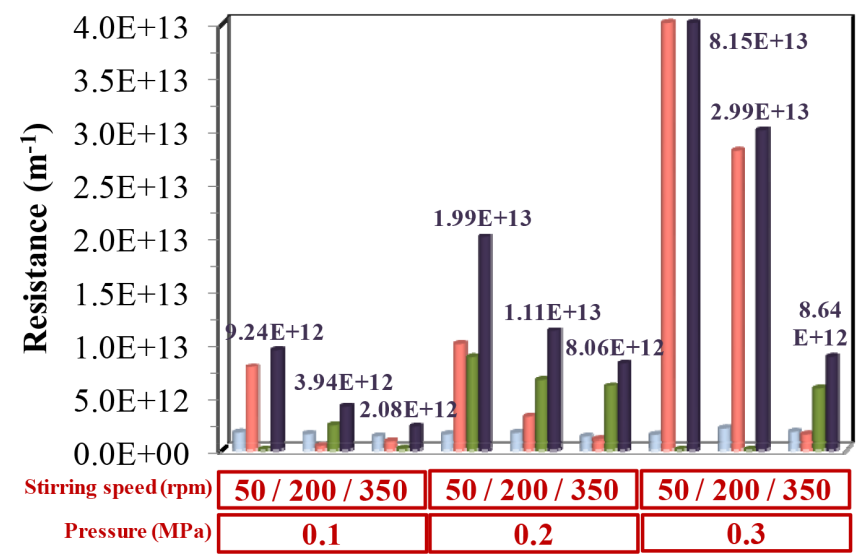

Fig. 3. Effect of stirring speed and transmembrane pressure on the resistances (a: without pre-ozonation; b: after pre-ozonation).

ozonized emulsions high irreversible resistance was measured (especially in case of higher pressures and/or lower stirring speeds), while during the filtration of original (not pretreated) emulsions reversible resistance was dominant. Since the oxidation of organic compounds increases their hydrophilic character, therefore higher adhesion ability of pre-ozonized oil droplets can be explained. Adhered oil layer was also confirmed visually in case of pre-ozonized water as it shown on Fig. 4.

Furthermore, pre-ozonation resulted in much higher negative surface charge of oil droplets, which caused higher stability and resulted in lower total resistance (because of the drastic reduction of reversible resistance) in case of 0.1 MPa transmembrane pressure (Fig. 3). However, at higher transmembrane pressures pre-ozonation increased the total resistance due to disintegrated oil droplets (which increase fouling), and higher adhesion ability of the droplets to the PES membrane.

Purification efficiencies were determined by measuring turbidity, extractable oil content, and chemical oxygen demand (COD) in all cases. Membrane separation and pre-ozonation $(t=5 \mathrm{~min})$ combined with membrane separation showed very similar performances. Purification efficiencies were higher than $92 \%$ based on COD values,

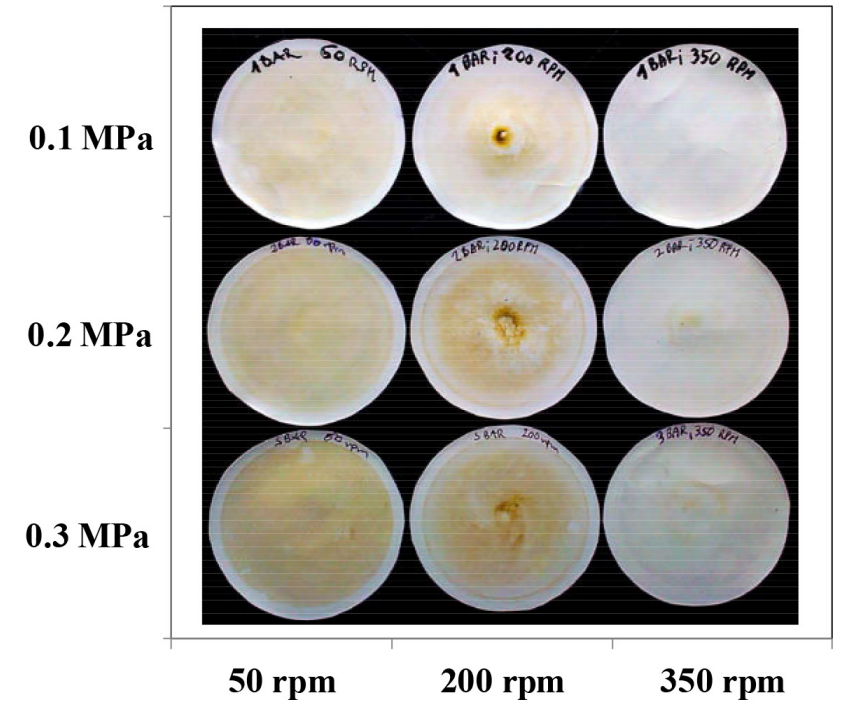

Fig. 4. Adhered oil layer on PES membranes after filtration of pre-ozonized oil in water emulsions.

and higher than $98 \%$ based on turbidity- and extractable oil content values in all cases. No significant differences were observed in connection with applied pressure, stirring speed or pre-ozonation.

\subsection{Effects of the duration of pre-ozonation}

After the determination of optimal parameters as $0.1 \mathrm{MPa}$ transmembrane pressure, $350 \mathrm{rpm}$ stirring speed and applying pre-ozonation, the effects of the duration of pre-ozonation were investigated. Oil in water emulsions were filtered after 0, 5, 10 and 20 min of pre-ozonation. Fig. 5 demonstrates the measured filtration resistances. Without pre-ozonation high reversible resistance was measured, which can be entirely eliminated by a short pre-ozonation treatment $(t=5 \mathrm{~min} ; 30 \pm$ $5 \mathrm{mg} \mathrm{L}^{-1}$ absorbed ozone) due to the change of Zeta-potential (from $-9,6 \mathrm{mV}$ to $-32 \mathrm{mV}$ ). This resulted in a notable reduc-

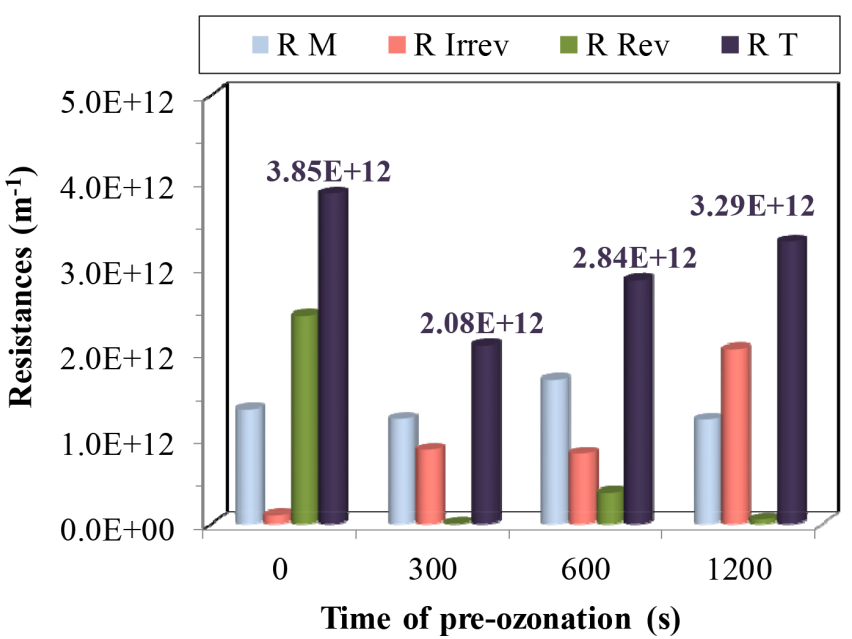

Fig. 5. Effects of the duration of pre-ozonation on the filtration resistances. 


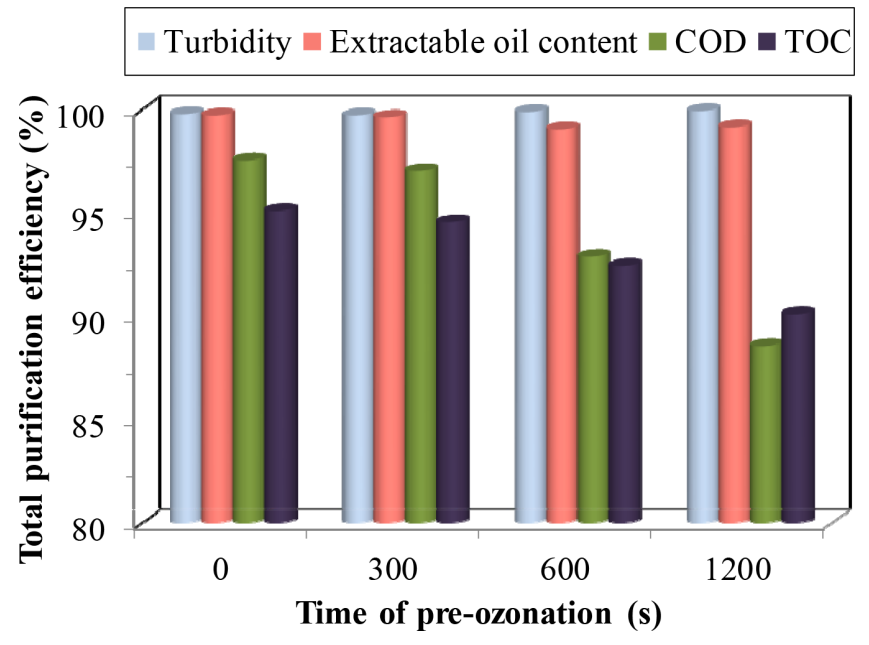

Fig. 6. Effects of the duration of pre-ozonation on the total purification efficiency.

tion of the total resistance. However irreversible resistance increased due to the smaller droplets and higher adhesion ability (caused by pre-ozonation). Increasing the duration of pre-ozonation irreversible resistance was growing further, since the previously mentioned effects were enhanced, therefore total resistance was also increased.

Purification efficiencies (Fig. 6.) were calculated from the turbidity, TOC, COD and TOG/TPH values using Eq. (1). On one hand, the purification efficiencies were higher than $99 \%$ in all cases in aspect of the turbidity because of the efficient filtration of oil droplets. On the other hand, longer pretreatments resulted in slightly higher extractable oil content and much higher COD and TOC values of the permeates (Fig. 6), because of increased amount of disintegrated $(\mathrm{d}<200 \mathrm{~nm})$ oil droplets (see Fig. 1$)$ and water soluble organic oxidation by-products generated by ozonation. Therefore, short pre-ozonation is recommended in relation to the purification efficiency.

\section{Conclusions}

Microfiltration using polyethersulfone membrane is a highly effective method to purify stable oil in water emulsions. Elimination efficiency was higher than $92 \%$ at all filtration conditions, with and without pre-ozonation.

Intensive stirring during filtration is important to avoid the oil layer formation on the surface of PES membrane, which results in flux declination. Transmembrane pressure higher than $0.1 \mathrm{MPa}$ is not beneficial because of much higher filtration resistance.

Even short duration of ozone pretreatment increased the negative charge of the surface of oil droplets which resulted in lower reversible filtration resistance and higher fluxes (in case of low transmembrane pressure) because of the increased stability of the emulsion. However pre-ozonation increased the irreversible filtration resistance due to disintegrated oil droplets and the adherence of oil droplets to the membrane surface. Moreover, longer ozonation resulted in lower purification efficiency because of generated dissolved organic compounds and disintegrated oil droplets.
Furthermore, short ozone pretreatment increases permeate flux only in case of low transmembrane pressure $(\sim 0.1 \mathrm{MPa})$, while at higher pressure oil droplets with decreased hydrophobicity can adhere onto the PES surface and smaller droplets increase fouling, which resulted in much higher total resistance.

Applying optimal pressure (0.1 MPa) and stirring intensity $(350 \mathrm{rpm})$ a short pre-ozonation resulted in $46 \%$ reduction of total filtration resistance without a notable change in the purification efficiency.

\section{Acknowledgements}

This project was supported by the János Bolyai Research Scholarship of the Hungarian Academy of Sciences. The authors are also grateful for the financial support provided by the project Hungarian Science and Research Foundation (NFKI contract number K112096).

\section{References}

[1] M. Padaki, R.S Murali, M.S. Abdullah, N. Misdan, A Moslehyani, M.A. Kassim, N. Hilal, A.F. Ismail, Membrane technology enhancement in oil-water separation. A review, Desalination, 357 (2015) 197-207.

[2] J. Yin, J. Zhou, Novel polyethersulfone hybrid ultrafiltration membrane prepared with $\mathrm{SiO}_{2}$-g-(PDMAEMA-co-PDMAPS) and its antifouling performances in oil-in-water emulsion application, Desalination, 365 (2015) 46-56.

[3] M.J. Um, S.H. Yoon, C.H. Lee, K.Y. Chung, J.J. Kim, Flux enhancement with gas injection in crossflow ultrafiltration of oily wastewater, Water Res., 35 (2001) 4095-4101.

[4] M. Cheryan, N. Rajagopalan, Membrane processing of oily streams. Wastewater treatment and waste reduction, J. Membr. Sci., 151 (1998) 1328.

[5] B. Chakrabarty, A.K. Ghoshal, M.K. Purkait, Ultrafiltration of stable oil-in-water emulsion by polysulfone membrane, J. Membr. Sci., 325 (2008) 427-437.

[6] H. Shokrkar, A. Salahi, N. Kasiri, T. Mohammadi, Prediction of permeation flux decline during MF of oily wastewater using genetic programming, Chem. Eng. Res. Des., 90 (2012) 846-853.

[7] C. Song, T. Wang, Y. Pan, J. Qiu, Preparation of coal-based microfiltration carbon membrane and application in oily wastewater treatment, Sep. Purif. Technol., 51 (2006) 80-84.

[8] A. Salahi, A. Gheshlaghi, T. Mohammadi, S.S. Madaeni, Experimental performance evaluation of polymeric membranes for treatment of an industrial oily wastewater, Desalination, 262 (2010) 235-242.

[9] M. Abbasi, A. Salahi, M. Mirfendereski, T. Mohammadi, A. Pak Dimensional analysis of permeation flux for microfiltration of oily wastewaters using mullite ceramic membranes, Desalination, 252 (2010) 113-119.

[10] M. Matos, C.F. García, M.A. Suárez, C. Pazos, J.M. Benito, Treatment of oil-in-water emulsions by a destabilization/ ultrafiltration hybrid process: Statistical analysis of operating parameters, J. Taiwan Inst. Chem. Eng., 59 (2016) 295-302.

[11] J. Benito, G. Ríos, E. Ortea, E. Fernández, A. Cambiella, C. Pazos, J. Coca, Design and construction of a modular pilot plant for the treatment of oil-containing wastewaters, Desalination, 147 (2002) 5-10

[12] A.B. Nordvik, J.L. Simmons, K.R. Bitting, A. Lewis, T. StrømKristiansen, Oil and water separation in marine oil spill clean-up operations, Spill Sci. Technol. Bulletin, 3 (1996) 107122.

[13] A.A. Al-Shamrani, A. James, H. Xiao, Destabilisation of oilwater emulsions and separation by dissolved air flotation, Water Res., 36 (2002) 1503-1512. 
[14] P. Cañizares, F. Martínez, C. Jiménez, C. Sáez, M.A. Rodrigo, Coagulation and electrocoagulation of oil-in-water emulsions, J. Hazard. Mater., 151 (2008) 44-51.

[15] M. Gryta, K. Karakrulski, The application of membrane distillation for the concentration of oil-water emulsions, Desalination, 121 (1999) 23-29.

[16] K. Masoudnia, A. Raisi, A. Aroujalian, M. Fathizadeh, A hybrid microfiltration/ultrafiltration membrane process for treatment of oily wastewater, Desal. Wat. Treat., 55 (2014) 901-912.

[17] F.L. Hua, Y.F. Tsang, Y.J. Wang, S.Y. Chan, H. Chua, S.N. Sin, Performance study of ceramic microfiltration membrane for oily wastewater treatment, Chem. Eng. J., 128 (2007) 169-175.

[18] H. Ohya, J.J. Kim, A. Chinen, M. Aihara, S.I. Semenova, Y Negishi, O. Mori, M. Yasuda, Effects of pore size on separation mechanisms of microoltration of oily water, using porous glass tubular membrane, J. Membr. Sci., 145 (1998) 1-14.

[19] S.R.H. Abadi, M.R. Sebzari, M. Hemati, F. Rekabdar T. Mohammadi, Ceramic membrane performance in microfiltration of oily wastewater, Desalination, 265 (2011) 222-228.

[20] Z.L. Kiss, L. Kocsis, G. Keszthelyi-Szabó, C. Hodúr, Z. László, Treatment of oily wastewater by combining ozonation and microfiltration, Desal. Wat. Treat., 55 (2014) 3662-3669.

[21] J. Lindau, A.-S. Jijnsson, Cleaning of ultrafiltration membranes after treatment of oily waste water, J. Membr. Sci., 87 (1994) 71-78.

[22] B. Chakrabarty, A.K. Ghoshal, M.K. Purkait, Cross-flow ultrafiltration of stable oil-in-water emulsion using polysulfone membranes, Chem. Eng. J., 165 (2010) 447-456.

[23] N. Moulai-Mostefa, O. Akoum, M. Nedjihoui, L. Ding, M.Y Jaffrin, Comparison between rotating disk and vibratory membranes in the ultrafiltration of oil-in-water emulsions, Desalination, 206 (2007) 494-498.

[24] X.S. Yi, S.L. Yu, W.X. Shi, N. Sun, L.M. Jin, S. Wang, B. Zhang, C. Ma, L.P. Sun, The influence of important factors on ultrafiltration of oil/water emulsion using PVDF membrane modified by nano-sized $\mathrm{TiO}_{2} / \mathrm{Al}_{2} \mathrm{O}_{3}$, Desalination, 281 (2011) 179-184.

[25] W. Chen, J. Peng, Y. Su, L. Zheng, L. Wang, Z. Jiang, Separation of oil/water emulsion using Pluronic F127 modified polyethersulfone ultrafiltration membranes, Sep. Purif. Technol., 66 (2009) 591-597.
[26] B. Hu, K. Scott, Influence of membrane material and corrugation and process conditions on emulsion microfiltration, J. Membr. Sci., 294 (2007) 30-39.

[27] B. Van der Bruggen, Chemical modification of polyethersulfone nanofiltration membranes: A review, J Appl Polym Sci, 114 (2009) 630-642.

[28] Y.G. Park, Effect of ozonation for reducing membrane-fouling in the UF membrane, Desalination, 147 (2002) 43-48.

[29] D. Metcalfe, P. Jarvis, C. Rockey, S. Judd, Pre-treatment of surface waters for ceramic microfiltration, Sep. Purif. Technol., 163 (2016) 173-180.

[30] S. Kertèsz, J. Cakl, H. Jiránková, Submerged hollow fiber microfiltration as a part of hybrid photocatalytic process for dye wastewater treatment, Desalination, 343 (2014) 106-112.

[31] L. De Angelis, M.M.F. de Cortalezzi, Improved membrane flux recovery by Fenton-type reactions, J. Membr. Sci., 500 (2016) 255-264.

[32] C.C. Kan, D.A.D. Genuino, K.K.P. Rivera, M.D.G. de Luna, Ultrasonic cleaning of polytetrafluoroethylene membrane fouled by natural organic matter, J. Membr. Sci., 497 (2016) 450-457.

[33] J. Guo, J. Hu, Y. Tao, J. Zhu, X. Zhang, Effect of ozone on the performance of a hybrid ceramic membrane-biological activated carbon process, J. Environ. Sci., 26 (2014) 783-791.

[34] A.L. Alpatova, S.H. Davies, S.J. Masten, Hybrid ozonationceramic membrane filtration of surface waters: The effect of water characteristics on permeate flux and the removal of DBP precursors, dicloxacillin and ceftazidime, Sep. Purif. Technol., 107 (2013) 179-186.

[35] S. Byun, J.S. Taurozzi, V.V. Tarabara, Ozonation as a pretreatment for nanofiltration: Effect of oxidation pathway on the permeate flux, Sep. Purif. Technol., 149 (2015) 174-182.

[36] H. Hyung, S. Lee, J. Yoon, C.-H. Lee, Effect of preozonation on flux and water quality in ozonation-ultrafiltration hybrid system for water treatment, Ozone: Sci. Eng., 22 (2000) 637-652.

[37] X. Cheng, H. Liang, A. Ding, F. Qu, S. Shao, B. Liu, H. Wang, D. Wu, G. Li, Effects of pre-ozonation on the ultrafiltration of different natural organic matter (NOM) fractions: Membrane fouling mitigation, prediction and mechanism, J. Membr. Sci., 505 (2016) 15-25.

[38] S. Kertész, Z. László, E. Forgács, G. Szabó, C. Hodúr, Dairy wastewater purification by vibratory shear enhanced processing, Desal. Wat. Treat., 35 (2012) 195-201. 